\title{
Surface removal of a copper thin film in an ultrathin water environment by a molecular dynamics study
}

\author{
Junqin SHI ${ }^{1}$, Liang FANG ${ }^{1,2, *}$, Kun SUN ${ }^{1, *}$, Weixiang PENG $^{1}$, Juan GHEN ${ }^{1}$, Meng ZHANG ${ }^{1}$ \\ ${ }^{1}$ State Key Laboratory for Mechanical Behavior of Materials, Xi'an Jiaotong University, Xi'an 710049, China \\ ${ }^{2}$ School of Mechanical and Electrical Engineering, Xiamen University Tan KahKee College, Zhangzhou 363105, China \\ Received: 16 August 2018 / Revised: 31 October 2018 / Accepted: 19 November 2018 \\ (C) The author(s) 2019.
}

\begin{abstract}
The surface planarity and asperity removal behavior on atomic scale in an ultrathin water environment were studied for a nanoscale process by molecular dynamics simulation. Monolayer atomic removal is achieved under both noncontact and monoatomic layer contact conditions with different water film thicknesses. The newly formed surface is relatively smooth without deformed layers, and no plastic defects are present in the subsurface. The nanoscale processing is governed by the interatomic adhering action during which the water film transmits the loading forces to the $\mathrm{Cu}$ surface and thereby results in the migration and removal of the surface atoms. When the scratching depth $\geq 0.5 \mathrm{~nm}$, the abrasive particle squeezes out the water film from the scratching region and scratches the $\mathrm{Cu}$ surface directly. This leads to the formation of trenches and ridges, accumulation of chips ahead of the particles, and generation of dislocations within the $\mathrm{Cu}$ substrate. This process is mainly governed by the plowing action, leading to the deterioration of the surface quality. This study makes the " $0 \mathrm{~nm}$ planarity, 0 residual defects, and 0 polishing pressure" in a nanoscale process more achievable and is helpful in understanding the nanoscale removal of materials for developing an ultra-precision manufacture technology.
\end{abstract}

Keywords: surface removal; monoatomic adhesion; copper thin film; ultrathin water film

\section{Introduction}

With the rapid development of ultra-precision manufacture technology (UMT) and miniaturized components, chemical mechanical polishing (CMP) technology has been widely applied in the semiconductor industry. Owing to the shrinkage of ultralarge-scale integrated circuits, new challenges for CMP have emerged recently, one of which is the small root-mean-square roughness (of the order of subnanometer) [1-4]. The initial requirement of reducing the step-height differences to about $50 \mathrm{~nm}$ was first changed to $30 \mathrm{~nm}$, then to $10 \mathrm{~nm}$, and finally to a $0 \mathrm{~nm}$ difference $[5,6]$. Furthermore, a three-"zero" target, namely, " $0 \mathrm{~nm}$ planarity, 0 defects, and 0 polishing load", is even proposed and desired to be reached by the year 2020 [5]. With this order of size, the removal of the polishing material within a few and even only one atomic layer of the film or coating surface is still challenging. In this case, as the polishing process occurs in the local area adjacent to the abrasive particles or cutting tool, the wear mechanism must differentiate it from the macroscopic world. Therefore, it is essential to completely understand the physical/chemical mechanisms of the wear underlying the CMP process and develop novel polishing approaches at the nanometer scale.

It is known that in a CMP process, one of the functional conditions is completely removing any excess surface and coating asperities while simultaneously controlling the dishing, erosion, and surface defects to be minimal [3]. In this case, a slurry including the abrasive particles and a chemical mixture is used to make the process efficient. Thus, the simultaneous

* Corresponding authors: Liang FANG, E-mail: fangl@xjtu.edu.cn; Kun SUN, E-mail: sunkun@mail.xjtu.edu.cn 
occurrence of mechanical wear by abrasive particles and chemical corrosion by the slurry solution make the CMP a comprehensive process with a chemical and mechanical synergy [7].

Regardless of the chemical erosion or reaction, the mechanical wear is affected by many variables in a typical polishing process such as process parameters including pressure, indentation depth, and velocity and other important parameters including the wafer nature, abrasive size, and abrasive geometry [1, 3, 8-11]. In addition, the slurry is another factor that has a significant effect on the polishing environment and makes the polishing process more complex [12-14]. As one of the simple but key components of a slurry, water not only carries the other components but also acts as an efficient lubricant, which affects the friction and wear behavior of the polished surface, material removal rate, and quality of the polished surface [15]. By studying the nanoscale friction and wear properties of silicon wafer, Chen et al. found that the wear rate and friction coefficient in water lubrication were lower and smaller, respectively, than those under dry friction conditions, and the wear mechanism of water lubrication was considered to be a molecule-scale removal process [16]. Although the study was focused on the synthetic function of the chemical and mechanical actions, its results can assist in this research to understand the friction and wear behavior of the waterlubricated surface. Ren et al. simulated an atomic force microscope (AFM)-based nanoscratching process with a water-layer lubrication by molecular dynamics (MD), and the results indicated that the water layer had a positive impact on the surface quality and a significant effect on the scratching forces (normal forces and tangential forces) [17]. We have investigated the effect of the water film thickness on the nanoscratch behavior in our previous work, and the results indicated that the removal efficiency of the surface atoms decreased with the water film thickness at a large scratching depth [18]. However, research on the mechanism of the effect of water on the polishing behaviors is still very limited. For instance, it is unclear whether the surface or coating asperities will be efficiently removed with minimized damage to the polished surface quality under a noncontact condition, as reported by Su [13]. Moreover, the interaction of water with the abrasive particle and polished material is still ambiguous, particularly for a polishing depth within a few and even only one atomic layer from the surface.

Therefore, to investigate the effects of the contact condition between the abrasive particle and surface atoms on the nanoscale process, we conducted a largescale three-dimensional MD simulation by sliding a diamond particle over a copper $(\mathrm{Cu})$ thin film with lubrication of an ultrathin water film. Because the material deformation, corrosive removal mechanism, surface defects, and scratching forces in the scratching process on the subnanometer scale should be different from those at a larger scale [4], various scratching depths less than or equal to $1 \mathrm{~nm}$ were adopted along with various thicknesses of the water film. The atomic removal process and structure of the newly formed surface were discussed under different conditions, and the mechanism of the nanoscale process was analyzed based on the atomic wear or removal behavior. Compared with the previous work [18], this work was focused on the removal process and mechanism of surface atoms to obtain a high-quality planarization at the nanoscale. This was expected to be helpful in revealing the role of water in the polishing process and understanding the friction and wear properties of the polished material.

\section{Simulation methodology}

It is known that it is difficult to consider the global planarization of the CMP process, which includes the complex chemical reactions and mechanical interactions between the abrasive particle, substrate, and chemistries, owing to the limitation of the potential functions and computational ability. Hence, a simplified model was proposed for the atomic-scale surface removal. The surface removal mechanism of nanometer $\mathrm{Cu}$ thin film under an ultrathin water environment was explored via MD simulation with LAMMPS. The single-circle polishing was represented by the nanoscratching process. The atomistic model of the simulation system is same as that in a previous investigation [18], as shown in Fig. S1 (in the Electronic Supplementary Material (ESM)), containing a diamond particle, water film, and monocrystalline $\mathrm{Cu}$ thin film. The initial distance between the spherical diamond abrasive particle and surface of water film is $2.0 \mathrm{~nm}$ longer than the cutoff distance. Because the abrasive particles in a 
nanoscale process are usually much harder than the machined $\mathrm{Cu}$ materials, the abrasive is regarded as a rigid body [19]. Herein, the ultrathin water film is used to reflect the low humidity or the adsorbed water molecules on the processed surface, which mimic a low water-lubricated environment. The $\mathrm{Cu}$ thin film is chosen as the polished material because it is the prior choice for the interconnection in the integrated circuit owing to its highly favorable electrical and electromigration resistance characteristics; however, its surface polish or process is very difficult [3]. The $\mathrm{Cu}$ thin film is in a perfect FCC (face-centered cubic) crystalline structure, and its dimensions along different crystal orientations are listed in Table 1. As displayed in Fig. S1 (in the ESM), several atomic layers at the bottom of the thin film are set to the boundary zone to eliminate the boundary effects, and the thermostat layer is set to imitate the heat dissipation. The motion of the atoms in the two upper zones obeys the classical Newton's second law and is integrated by the velocityverlet algorithm. Lateral periodic boundary conditions are adopted for the simulated system. Other details of the model of the MD simulations are presented in Table S1 (in the ESM).

The atomic interaction is one of the key factors influencing the reliability of the simulation results. The interactive forces between the $\mathrm{Cu}$ atoms are derived from the embedded atom method (EAM) potential, which has been proved to be an accurate potential for describing metallic cohesion and avoiding ambiguity [20]. The Morse potential [21] is used to depict the $\mathrm{Cu}-\mathrm{C}$ interaction, and the corresponding parameters are listed in Table S1 (in the ESM), which have been validated by research $[22,23]$. The $\mathrm{C}-\mathrm{C}$ interaction is not calculated based on the treatment of a rigid body.
The rigid TIP4P interaction model [24, 25] is used for the condensed water film. The $\mathrm{Cu}-\mathrm{O}$ and $\mathrm{C}-\mathrm{O}$ interactions are defined by the Lennard-Jones potential, and the Lorentz-Berthelot mixing rules $[17,26]$ are used to generate the relevant parameters as listed in Table S1 (in the ESM). In addition, the interactions of the $\mathrm{H}$ atoms in the water molecules with other types of atoms are also not considered because they are intra-molecular long-ranged electrostatics and have a very weak impact on the results [17].

The MD simulations in this work include three steps. The first step is the relaxation of the initial system for 50 ps to minimize the system energy by using NVT (canonical ensemble) ensemble and the Nose-Hoover thermostat. The second step is the nanoindentation process, during which a constant velocity of $10 \mathrm{~ms}^{-1}$ is used to pressure the nanoparticles in the $\mathrm{Cu}$ substrate. Finally, the abrasive particle scratches the $\mathrm{Cu}$ surface at a constant indentation depth and moving velocity of $10 \mathrm{~ms}^{-1}$ with NVE (microcanonical ensemble) ensemble. In the second step, the nanoindentation process is stopped when the shortest distance between the $\mathrm{Cu}$ surface and outer atoms of the abrasive particle reaches a preset depth, which is maintained by controlling the position of the center of the mass of the abrasive particle in the nanoscratching process. This models the mechanical abrasion and planarization of the monocrystalline $\mathrm{Cu}$ surface, as may be the case in the nanoscale process. The Langevin thermostat in NVE ensemble is used to control the temperature of $300 \mathrm{~K}$ for the thermostat layer and water film. Various water film thicknesses $(0 \mathrm{~nm}, 0.3 \mathrm{~nm}, 0.5 \mathrm{~nm}$, and $1.0 \mathrm{~nm})$ and scratching depths $(-0.2 \mathrm{~nm}, 0.1 \mathrm{~nm}, 0.5 \mathrm{~nm}$, and $1.0 \mathrm{~nm}$ ) are used to reveal the effect of the water film thickness on the atomic removal behavior, as

Table 1 Average interaction forces along the scratching direction.

\begin{tabular}{|c|c|c|c|c|}
\hline $\begin{array}{l}\text { Water film thickness } \\
\qquad(\mathrm{nm})\end{array}$ & $\begin{array}{l}\text { Scratch depth } \\
\quad(\mathrm{nm})\end{array}$ & $\begin{array}{l}\text { Water-Cu interaction } \\
\qquad(\mathrm{nN})\end{array}$ & $\begin{array}{l}\text { Water-particle } \\
\text { interaction }(\mathrm{nN})\end{array}$ & $\begin{array}{c}\text { Particle- } \mathrm{Cu} \text { interaction } \\
\qquad(\mathrm{nN})\end{array}$ \\
\hline & -0.2 & 7.70 & 9.24 & 1.23 \\
\hline \multirow[t]{3}{*}{0.3} & 0.1 & 10.41 & 11.26 & 21.96 \\
\hline & 0.5 & 4.48 & 5.40 & 86.94 \\
\hline & -0.2 & 17.29 & 16.17 & 0.73 \\
\hline \multirow[t]{2}{*}{0.5} & 0.1 & 16.28 & 17.80 & 20.12 \\
\hline & 0.5 & 7.02 & 6.52 & 90.08 \\
\hline 1.0 & -0.2 & 41.52 & 46.08 & 0.18 \\
\hline
\end{tabular}


presented in Table S1 (in the ESM). The dislocation extraction algorithm [27, 28] and Ovito [29] software are used to identify the dislocation defects and visualize the simulation results, respectively.

\section{Results and discussions}

It has been approved by increasingly more researchers that the scratching depth during CMP can be of the order of subnanometer. For example, the indentation depth of a particle with a diameter of $50 \mathrm{~nm}$ analyzed by Luo and Dornfeld [1,30] was approximately $0.07 \mathrm{~nm}$ in the CMP process. At the scratching depth of subnanometer, the polishing behaviors should be different from those at relatively larger depths [4]. Thus, to reveal the physical essence underlying the CMP process, we adopted four scratching depths of $-0.2 \mathrm{~nm}, 0.1 \mathrm{~nm}, 0.5 \mathrm{~nm}$, and $1.0 \mathrm{~nm}$ to study the interactions between the particle, water film, and $\mathrm{Cu}$ thin film. Here, the scratching depth is defined as the distance that the surface atoms of the particle penetrate in the $\mathrm{Cu}$ surface. The negative value $-0.2 \mathrm{~nm}$ indicates that the particle does not penetrate the $\mathrm{Cu}$ substrate, implying that there exists a noncontact between the particle and polished surface, whereas the value of 0.1 corresponds to a monoatomic layer contact. Here, to describe the surface removal process clearly, the removed atoms are defined as the ones that are removed from their original positions and finally moved to the top of the original surface, and their location is higher than threshold height $h=0.18 \mathrm{~nm}$ (about half of the lattice of monocrystalline $\mathrm{Cu}$ ) according to the Refs. [11, 18]. In comparison, the atoms are defined as deformed atoms when their original positions are changed but the final location is not higher than the threshold height $h$.

Figure 1 shows the worn morphology of the crosssectional views of the $x z$ plane and plane views of the $x y$ plane, where the surface atoms in yellow color are only displayed and the water film of $1.0 \mathrm{~nm}$ thickness is omitted. Figure S2 (in the ESM) shows a slice configuration with $0.5 \mathrm{~nm}$ thickness in the $x z$ plane. In Fig. 1(a), it can be seen that in the scratching region, some initial surface atoms are removed and lifted above the $\mathrm{Cu}$ surface after the particle passes by. Hence, a new surface layer (that originally existed beneath

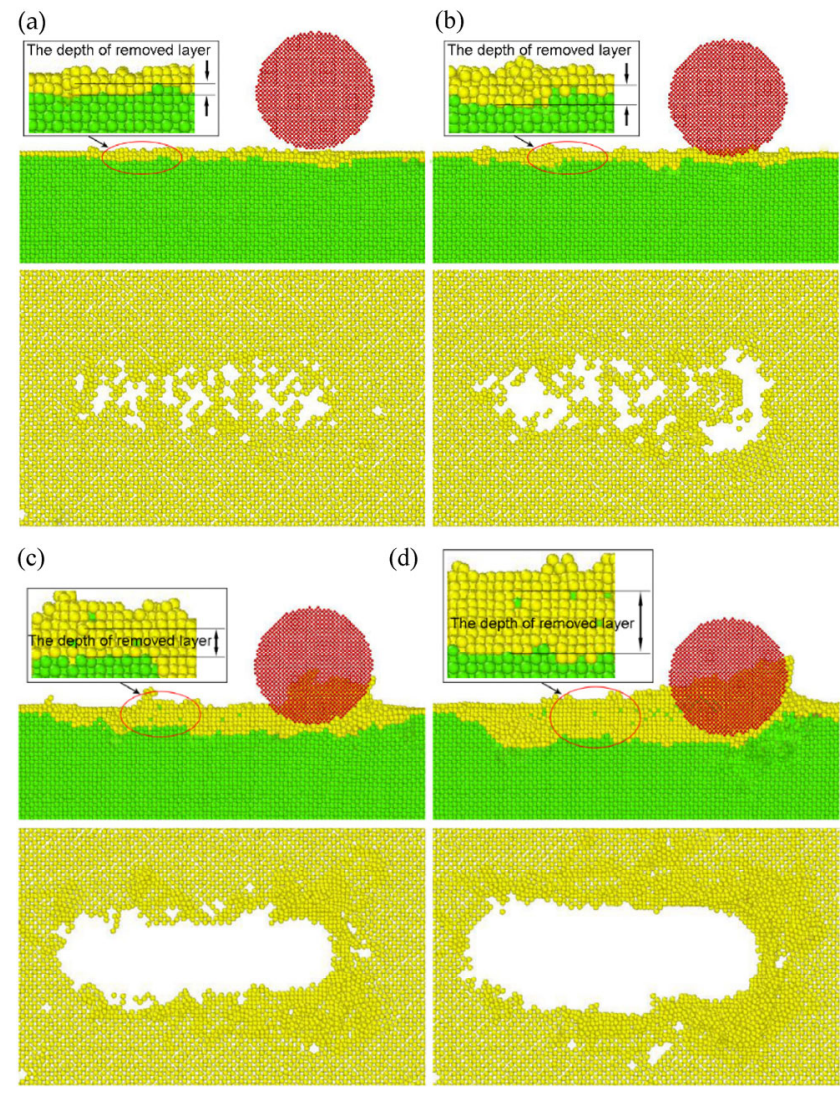

Fig. 1 Snapshots of the worn morphology of the cross-sectional views of the $x z$ plane and plane views of the $x y$ plane with the omission of the water film of $1.0 \mathrm{~nm}$ thickness, under various scratching depths (h): (a) $-0.2 \mathrm{~nm}$; (b) $0.1 \mathrm{~nm}$; (c) $0.5 \mathrm{~nm}$; and (d) $1.0 \mathrm{~nm}$, at a scratching distance of $9 \mathrm{~nm}$. Color code: yellowsurface $\mathrm{Cu}$ atoms; green-other $\mathrm{Cu}$ atoms; red-abrasive particle. The water film is omitted for clarity.

these removed surface atoms and in which all the new surface atoms are firstly exposed) appears on the initial subsurface of the $\mathrm{Cu}$ thin film. Figure S2(a) indicates that many surface atoms are removed or deformed from their original positions, leading to the formation of vacancies on the surface, as shown from the plane views. Therefore, it is considered that one monoatomic layer is removed from the initially perfect $\mathrm{Cu}$ substrate at the scratching depth of $-0.2 \mathrm{~nm}$. This manner of monolayer material removal also occurs at the scratching depth of $0.1 \mathrm{~nm}$, as shown in Figs. 1(b) and S2(b) (in the ESM). The newly formed surface is not very flat in the local scratching region under the monoatomic layer contact condition. However, the step-height difference in the entire scratching region is relatively close to uniformization within one monoatomic layer, as shown in the cross-sectional 
views in Figs. 1(a) and 1(b). This suggests that the polishing quality of the $\mathrm{Cu}$ surface is very close to the target of "0 $\mathrm{nm}$ planarity" under the noncontact or monoatomic surface contact condition. The removed $\mathrm{Cu}$ atoms are in a monoatomic form or a cluster formed by a few atoms, as shown in the inset, which is consistent with the removal of silicon atoms with an indentation depth of $0.1 \mathrm{~nm}$ as reported in Ref. [4]. In the real CMP process, the slurry and water continuously flow owing to the pad rotation, so that the removed material in the aforementioned form is taken away rapidly [31].

Figures 1(c) and 1(d) show the worn morphology with a scratching depth up to $0.5 \mathrm{~nm}$ and $1.0 \mathrm{~nm}$. It is clear that owing to the increase in the scratching depth, the abrasive particle contacts more $\mathrm{Cu}$ atoms and thereby results in a larger vacancy zone. Moreover, practically all of the surface $\mathrm{Cu}$ atoms in contact with the particle are removed and deformed during the scratching process (as displayed in Figs. S2(c) and S2(d) (in the ESM)). As the particle moves forward, numerous deformed and removed atoms accumulate to form clusters or chips ahead of the particle. Concurrently, remarkable ridges (i.e., pile-up of atoms) along both the left and right sides of the particle are produced, particularly at the scratching depth of $1.0 \mathrm{~nm}$, as shown in Fig. S3 (in the ESM). After the particle passes by, a groove is formed. These results are in well agreement with the dry nanoscratching process as shown in Fig. S2(c) (in the ESM) as well as the AFM-based nanoscratching process with water-layer lubrication [17]. Based on the distribution of the surface $\mathrm{Cu}$ atoms shown in yellow color in the cross-sectional views, the bottom of the groove exhibits obvious atomic steps and the ridge is non-uniform in height. In addition, although the removal rate of the surface atoms increases obviously with the scratching depth increasing to $0.5 \mathrm{~nm}$ and $1.0 \mathrm{~nm}$, the height difference between the groove and ridge is dramatically increased, indicating that a deep scratching depth damages the surface quality. This is in contrast with the case of a small scratching depth of $-0.2 \mathrm{~nm}$ and $0.1 \mathrm{~nm}$, where only a monoatomic layer is removed and no obvious groove and ridge are formed, as shown in Figs. 1(a) and 1(b), and Figs. S2(a) and S2(b) (in the ESM).

To evaluate the effect of the water film thickness on the removal process and surface quality, we also conducted MD simulations of the nanoscratching process under a water film thickness of $0.3 \mathrm{~nm}$ and $0.5 \mathrm{~nm}$, approximately corresponding to a monolayer and bilayer water film, as well as dry nanoscratching. The snapshots of the worn morphology are displayed in Figs. 2, S4, and S5 (in the ESM). Figures 2 and S4 (in the ESM) indicate that a one-atom-thin layer is removed after scratching with different scratching depths and water film thicknesses, which is almost the same with the simulated results under a water film thickness of $1.0 \mathrm{~nm}$ in Figs. 1(a) and 1(b). For the dry nanoscratching presented in Fig. S5 (in the ESM), the monoatomic layer removal only occurs at a scratching depth of $0.1 \mathrm{~nm}$, whereas the $\mathrm{Cu}$ surface still maintains its perfect lattice structure at a scratching depth of $-0.2 \mathrm{~nm}$ owing to the weak interaction between the particle and $\mathrm{Cu}$ substrate. Comparing the plane views in Figs. 1(a) and 1(b), 2, and S5(b) (in the ESM), it can

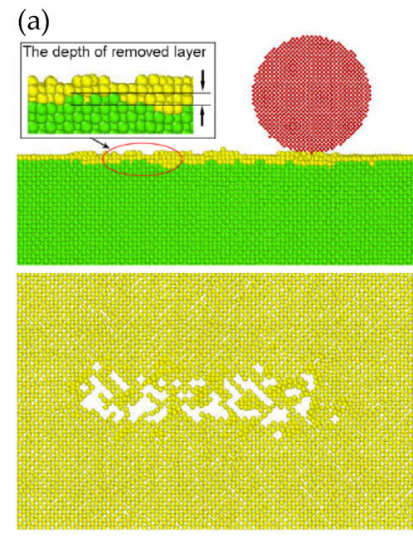

(c)
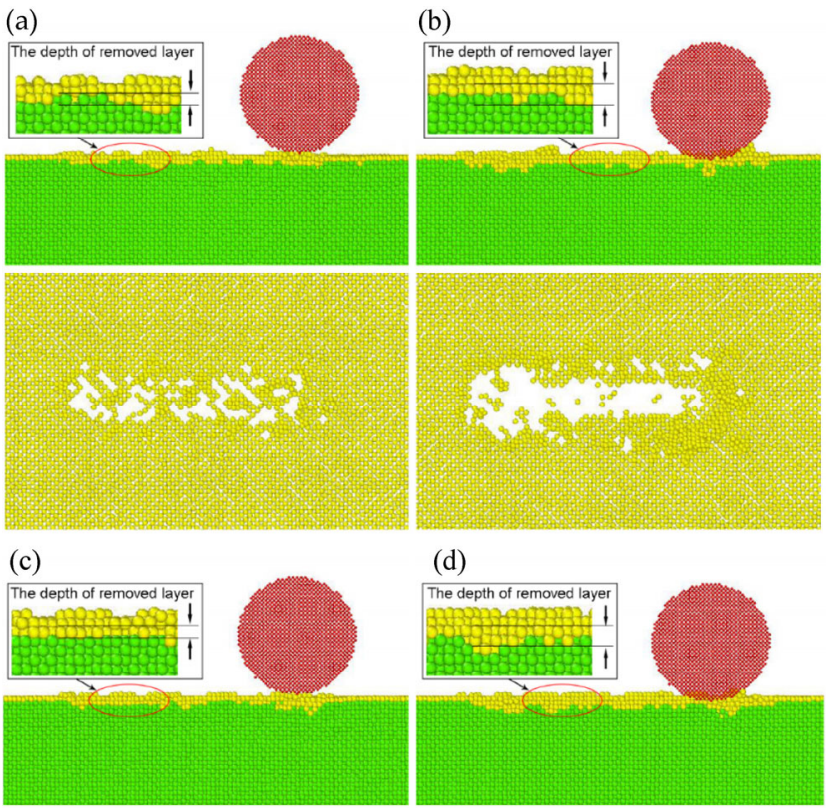

(d)

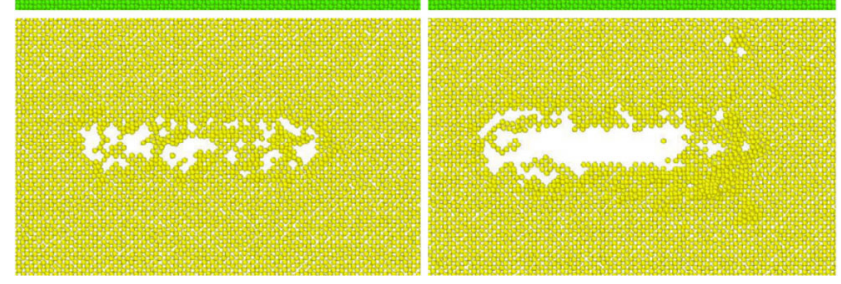

Fig. 2 Snapshots of the worn morphology of the cross-sectional views of the $x z$ plane and plane views of the $x y$ plane with omission of the water film, under various water film thicknesses $(H)$ and scratching depths $(h), H=0.5 \mathrm{~nm}$ : (a) $h=-0.2 \mathrm{~nm}$, (b) $h=0.1 \mathrm{~nm}$; $H=0.3 \mathrm{~nm}$ : (c) $h=-0.2 \mathrm{~nm}$, (d) $h=0.1 \mathrm{~nm}$. The water film is omitted for clarity. 
be seen that the surface vacancy formed by the atomic removal and deformation in the scratching region becomes more obvious as the water film thickness decreases from $1.0 \mathrm{~nm}$ to $0 \mathrm{~nm}$. This indicates that the number of removed atoms in the central region of the scratching increases with the decrease in the water film thickness. However, on contrast, the area of the scratching region slightly decreases with the decrease in the water film thickness at the same scratching depth.

Furthermore, to reveal the mechanism of the material removal, the worn configurations with the presence of the water film and local interaction zones were extracted and are shown in Fig. 3. The number of water molecules remaining in the scratching region is calculated in Fig. 4. According to Fig. 3, the water molecules are adsorbed on the $\mathrm{Cu}$ surface in an ordered, layered, crystalline, or commensurate structure, similar to other studies that mainly focused on water adsorption on a metal surface [32-36]. We can also find that a small number of water molecules are accumulating in front of the particle when the scratching depth is -0.2 $\mathrm{nm}$ and $0.1 \mathrm{~nm}$, whereas the number of accumulated water molecules increases considerably with a scratching depth of up to $0.5 \mathrm{~nm}$ and $1.0 \mathrm{~nm}$. In contrast, the number of water molecules remaining in the scratching region decreases dramatically with the increasing scratching depth, as displayed in the plane views in Figs. 3 and 4. In particular, the number of water molecules under the noncontact condition is about quadruple that at the scratching depth of $0.1 \mathrm{~nm}$; however, no major difference in the wear of the $\mathrm{Cu}$ thin film is observed as mentioned above. This indicates that these water molecules remaining in the scratching region play a predominant role at a shallower scratching depth during the monoatomic layer removal.

For the scratching process under a noncontact condition (the scratching depth of $-0.2 \mathrm{~nm}$ ) with a water film thickness of $1.0 \mathrm{~nm}$, the cross-sectional view in Fig. 3(a) shows that the space between the particle and $\mathrm{Cu}$ surface is occupied by numerous remaining water molecules. The average interaction forces listed in Table 1 manifest that the interactive force of the particle- $\mathrm{Cu}$ film $(0.18 \mathrm{nN})$ is much less than the interactive forces of both water- $\mathrm{Cu}(41.52 \mathrm{nN})$ and water-particle $(46.08 \mathrm{nN})$. These results indicate that the monoatomic layer removal should be ascribed to (a)

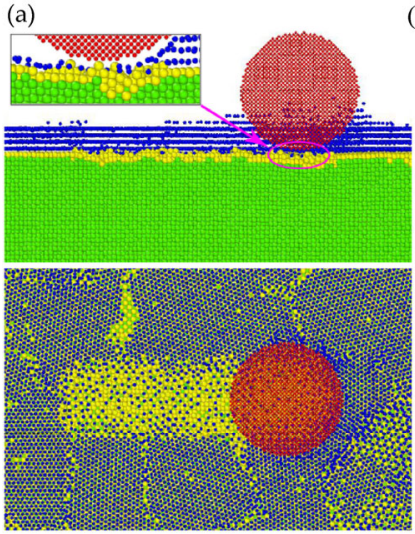

(b)
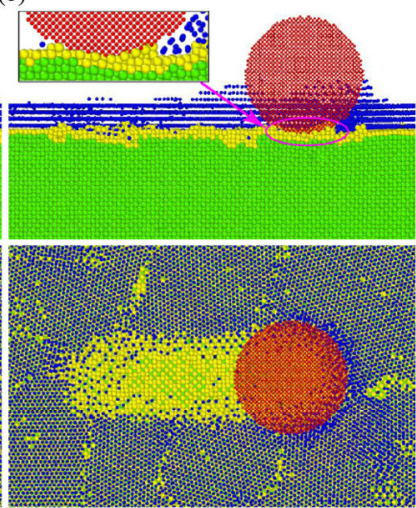

(c)
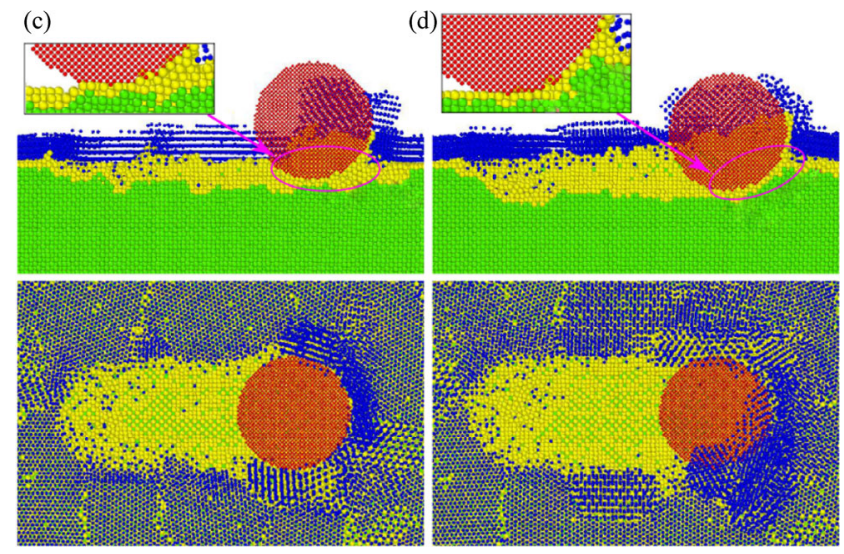

Fig. 3 Snapshots of the worn configuration of the cross-sectional views of the $x z$ plane and plane views of the $x y$ plane under various scratching depths (h): (a) $-0.2 \mathrm{~nm}$, (b) $0.1 \mathrm{~nm}$, (c) $0.5 \mathrm{~nm}$, and (d) $1.0 \mathrm{~nm}$, at a scratching distance of $9 \mathrm{~nm}$, with water film thickness of $1.0 \mathrm{~nm}$. The blue represents the oxygen atoms in the water molecules.

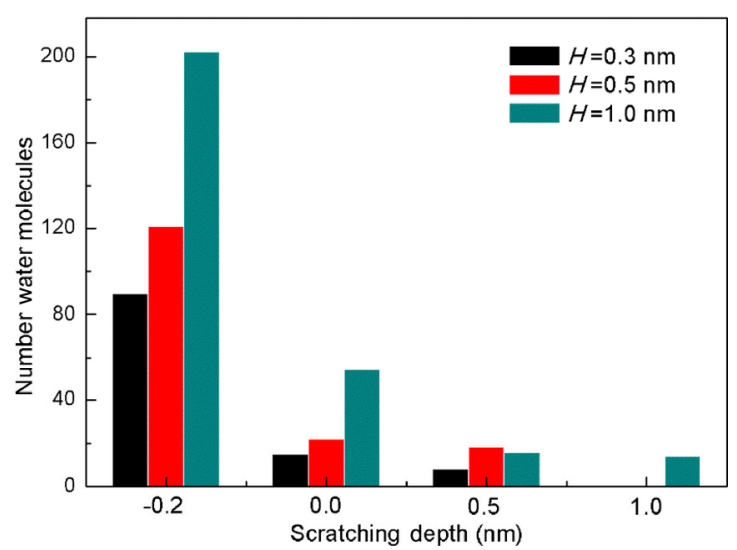

Fig. 4 Number of water molecules within the groove region at various scratching depths and water film thicknesses.

the water-Cu interactive force. Figure 5 displays the atomic removal process at a scratching depth of -0.2 $\mathrm{nm}$ and water film thickness of $1.0 \mathrm{~nm}$ at different simulation times, where the three oxygen atoms and 


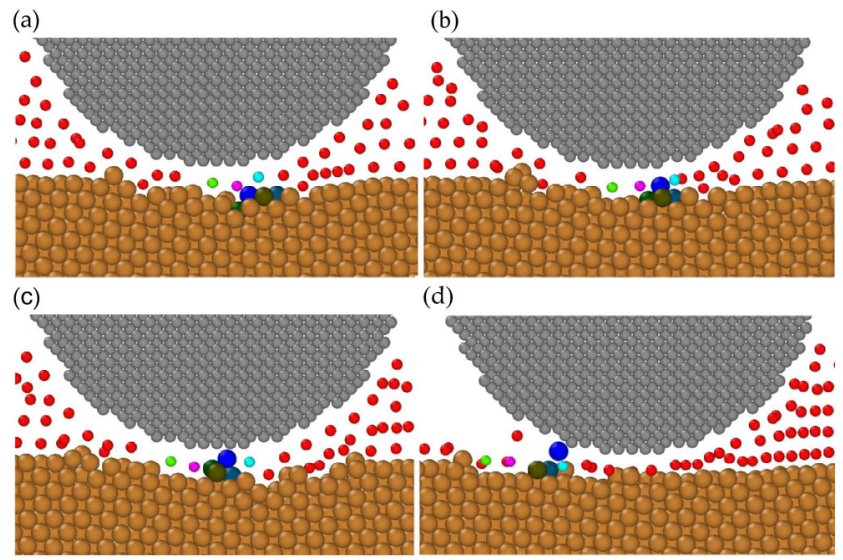

Fig. 5 Snapshots of the atomic removal process within a $5 \mathrm{~nm}$ slice of the scratching central region, at different simulated times: (a) $5 \mathrm{ps}$, (b) $15 \mathrm{ps}$, (c) $35 \mathrm{ps}$, and (d) $100 \mathrm{ps,} \mathrm{with} \mathrm{a} \mathrm{scratching} \mathrm{depth}$ of $-0.2 \mathrm{~nm}$ and water film thickness of $1.0 \mathrm{~nm}$. Color code: red, oxygen atoms in water molecule; gray, abrasive particle; dark yellow, $\mathrm{Cu}$ atoms. To describe the atomic removal process in detail, three oxygen atoms are marked with purple, green, and light blue colors, and four $\mathrm{Cu}$ atoms are marked with blue, dark green, antique bronze, and Bangladesh green colors.

$\mathrm{Cu}$ atoms around the blue $\mathrm{Cu}$ atom are marked with other colors. The $\mathrm{Cu}$ surface beneath the particle shows a slight deformation because the water molecules under the particle can transmit the force from the loading of the particle to the $\mathrm{Cu}$ surface. From 5 ps to $15 \mathrm{ps}$ and then to $35 \mathrm{ps}$, the blue $\mathrm{Cu}$ atom is gradually pushed or attracted by the water molecules (oxygen atoms marked in purple and light blue). Once the water- $\mathrm{Cu}$ interactive force is larger than the force that is sufficient to break the metallic bond of $\mathrm{Cu}$, the $\mathrm{Cu}$ atoms are removed from their initial positions and even adhere to the particle. For instance, the position of the blue $\mathrm{Cu}$ atoms is higher than that in the original $\mathrm{Cu}$ surface at 100 ps, as shown in Fig. 5(d). This type of removal behavior continuously occurs in the nanoscratching process. In this process, the adhesion and removal of the surface atoms only cause the surface structure to change, resulting in a surface roughness on the order of atomic size magnitude, which is consistent with the research results in Refs. $[1,4,30]$. A similar removal behavior of the surface atoms also occurs in the scratching process with a scratching depth of $0.1 \mathrm{~nm}$. Concurrently, the adhering action of the $\mathrm{Cu}$ atoms to the particle increases obviously, which is validated by the interactive force of the particle- $\mathrm{Cu}(18.44 \mathrm{nN})$, thus leading to an increase in the removed atoms and area of the scratching region, as displayed in Fig. 1(b). Moreover, the monocrystalline $\mathrm{Cu}$ substrate is divided into several zones marked with different colors and numbers $1-6$ before the nanoscratching process depicted in Fig. 6 . It can be seen from circle A in Fig. 6(b) that some dispersive $\mathrm{Cu}$ atoms or small atom clusters are shifted from their original positions in zone 2 and zone 5 and then appear in zone 3 and zone 6 , but no chips or debris formation are observed. Fewer atoms shift at a scratching depth of $-0.2 \mathrm{~nm}$ in Fig. 6(a). It is worth to note that the water molecules confined between the particle and $\mathrm{Cu}$ surface could be solidified under pressure and then come into rigid adhesive contact with the $\mathrm{Cu}$ atoms, in well agreement with other reports in Refs. [17, 37, 38]. These results provide more evidence manifesting that the surface atoms are removed by the adhering action (Fig. 5) under the noncontact and monoatomic layer contact conditions during the CMP process.
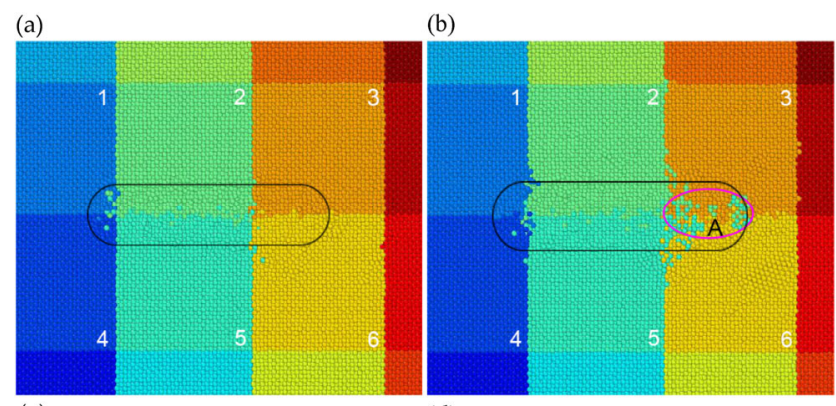

(c) (d)
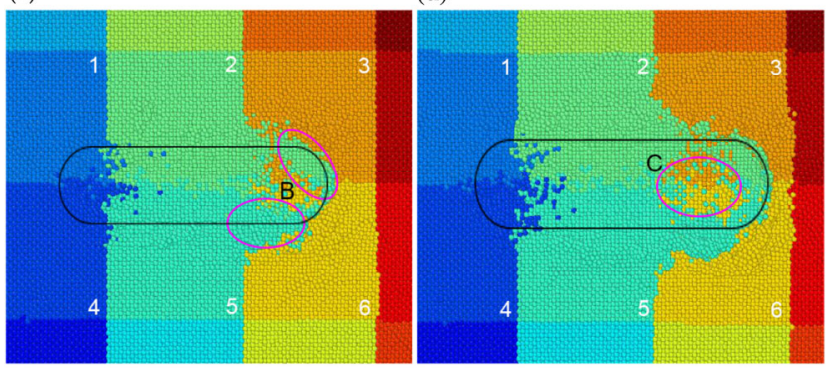

Fig. 6 Snapshots of the worn configuration of the top views of the scratching surface for various scratching depths $(h)$ : (a) $-0.2 \mathrm{~nm}$, (b) $0.1 \mathrm{~nm}$, (c) $0.5 \mathrm{~nm}$, (d) $1.0 \mathrm{~nm}$, at a scratching distance of $9 \mathrm{~nm}$, with a water film thickness of $1.0 \mathrm{~nm}$. The black line marks the scratching contour. To display the atomic shift and removal, the surface is separated into several zones marked by different colors, and the atomic removal and shift occur in 6 zones marked by numbers $1-6$. The water film is omitted for clarity. The purple ellipse marked with A, B, and C in (a), (b), and (c) is used to mark the regions where the surface atoms are shifted and removed severely. 
As the scratching depth increases to $0.5 \mathrm{~nm}$ and $1.0 \mathrm{~nm}$, most of the water molecules under the particle are squeezed out from the scratching region (as proved by the number of water molecules in Fig. 4), and the particle contacts the $\mathrm{Cu}$ surface directly, as displayed in Figs. 3(c) and 3(d). The interactive water-Cu and water-particle forces decrease rapidly, whereas the particle- $\mathrm{Cu}$ forces increase dramatically (in Table 1). Particularly, at a scratching depth of $1.0 \mathrm{~nm}$, the interactive particle- $\mathrm{Cu}$ force $(147.98 \mathrm{nN})$ becomes much larger than the other two forces (4.24 and $13.12 \mathrm{nN}$ ) but remains very close to the interactive particle-Cu force (158 $\mathrm{nN}$ ) for dry nanoscratching. This suggests that the direct interaction between the abrasive particle and $\mathrm{Cu}$ thin film predominantly governs the material removal. This is in contrast to that occurring at a scratching depth of less than or equal to $0.1 \mathrm{~nm}$. During the moving forward of the particle, one amorphous layer is formed, the deformation zone in the $\mathrm{Cu}$ film increases, and several chips or debris are generated in front of the particle, as shown in Figs. 6(c) and 6(d). Concurrently, a fraction of the $\mathrm{Cu}$ atoms is shifted from its original positions in zone 2 and zone 5 and appears underneath the particle in zone 3 and zone 6 , as enclosed in circle C in Fig. 6(d). All these chips, amorphous layers, grooves, and ridges are actually caused by the abrasive particle continuously plowing or cutting the $\mathrm{Cu}$ surface. Therefore, it is thought that the surface atoms are mainly removed by the ploughing action at a deep scratching depth. The ploughing leads to the structural changes of the $\mathrm{Cu}$ thin film that is not only near the surface but also in the deep region. The surface quality deteriorates with larger surface roughness, as shown in Figs. 1(c) and 1(d), and Figs. 3(c) and 3(d).

Figure 7 presents the nanoscratching results with monolayer and bilayer water films. It is clear that the distribution of the water molecules around the particle at both the scratching depths $(-0.2 \mathrm{~nm}$ and $0.1 \mathrm{~nm})$ is similar to that under the water film thickness of $1.0 \mathrm{~nm}$ (in Figs. 3(a) and 3(b)). In comparison, the number of water molecules remaining in the scratching region decreases further with the decrease in the water film thickness from $1.0 \mathrm{~nm}$ to $0.3 \mathrm{~nm}$, as validated by the number in Fig. 4. The insets in Figs. 7(a) and 7(c) show that some of the water molecules still remain beneath the particle and more water molecules exist in the space ahead of the particle. All those water molecules play an important role in facilitating the removal of the monoatomic layer. Contrarily, with the scratching depth increasing to $0.1 \mathrm{~nm}$ in Figs. $7(\mathrm{~b})$ and 7 (d), there are only a small number of water molecules remaining beneath the particle, and thus, the particle starts to contact the surface $\mathrm{Cu}$ atoms, similar to the dry nanoscratching in Fig. S5(b) (in the ESM). The average interaction forces listed in Table 1 indicate that the water- $\mathrm{Cu}$ and water-particle interactive forces decrease, whereas the particle- $\mathrm{Cu}$ interactive forces increase slightly with the water film thickness decreasing to $0.5 \mathrm{~nm}$ and $0.3 \mathrm{~nm}$. For example, at a scratching depth of $0.1 \mathrm{~nm}$, as the water film thickness decreases from $1.0 \mathrm{~nm}$ to $0.5 \mathrm{~nm}$ and then to $0.3 \mathrm{~nm}$, the interactive water-Cu force decreases from $39.44 \mathrm{nN}$ to $16.28 \mathrm{nN}$ and then to $10.41 \mathrm{nN}$; however, the interactive particle$\mathrm{Cu}$ forces are $18.44 \mathrm{nN}, 20.12 \mathrm{nN}$, and $21.96 \mathrm{nN}$, respectively. Clearly, the interactive particle-Cu force

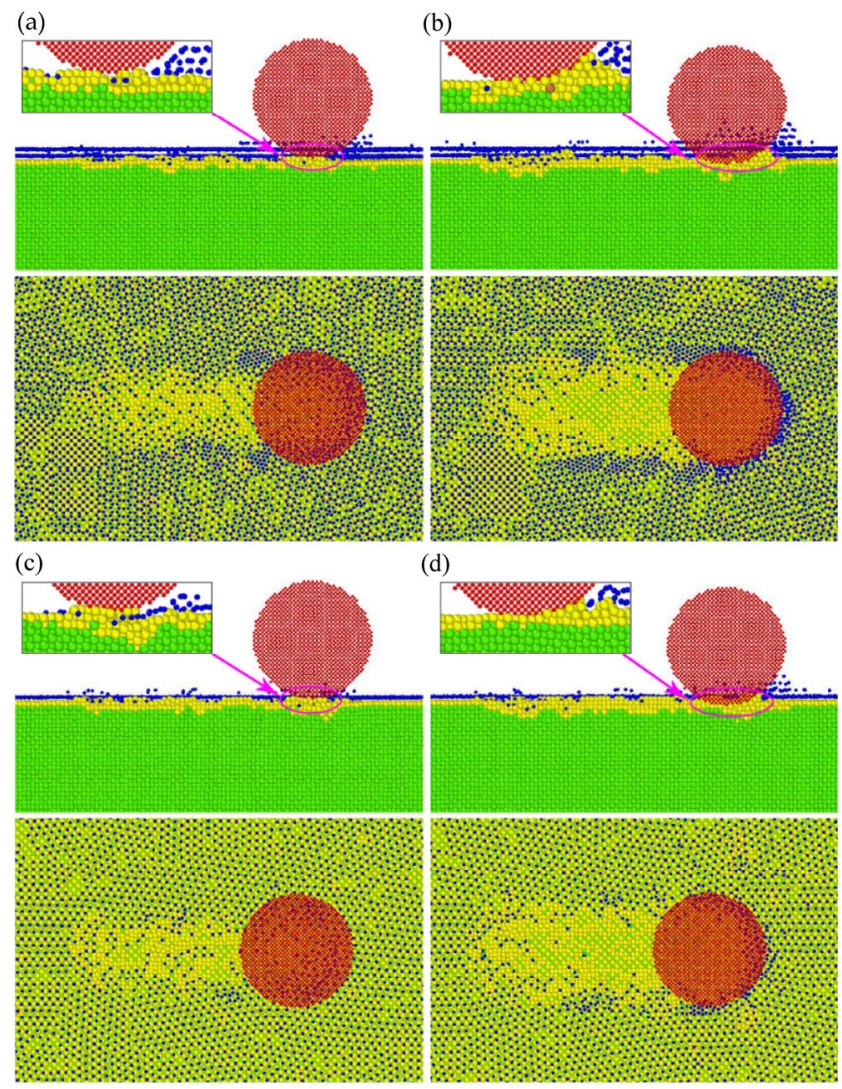

Fig. 7 Snapshots of the worn configuration of the cross-sectional views of the $x z$ plane and plane views of the $x y$ plane under various water film thicknesses $(H)$ and scratching depths $(h), H=$ $0.5 \mathrm{~nm}$ : (a) $h=-0.2 \mathrm{~nm}$, (b) $h=0.1 \mathrm{~nm} ; H=0.3 \mathrm{~nm}$ : (a) $h=-0.2 \mathrm{~nm}$, (b) $h=0.1 \mathrm{~nm}$. 
becomes comparable with and even larger than twice the interactive water- $\mathrm{Cu}$ force for the water film thickness of $0.5 \mathrm{~nm}$ and $0.3 \mathrm{~nm}$, respectively. These results indicate that the contribution of the water film to the removal of the monoatomic layer decreases, whereas the adhering action of the $\mathrm{Cu}$ atoms to the abrasive particle increases for thinner water films. In addition, in the cases when both the water film thickness and scratching depth are very small $(H=$ $0.5 \mathrm{~nm}$ or $0.3 \mathrm{~nm}$ and $h=-0.2 \mathrm{~nm}$ and $0.1 \mathrm{~nm}$ ), the interaction forces for both water- $\mathrm{Cu}$ and particle- $\mathrm{Cu}$ are relatively small (in Table 1), even smaller than the metallic bond strength of $\mathrm{Cu}$. Therefore, it seems very difficult to remove the $\mathrm{Cu}$ atoms from their original positions. However, it should be noted that the removal is a continuous process, namely, one $\mathrm{Cu}$ atom is scratched by different water molecules and the $\mathrm{C}$ atoms in the particle is used many times during the scratching process, as shown in Fig. 5. Therefore, the surface $\mathrm{Cu}$ atoms can be removed individually under the conditions of a thin water film and shallow scratching depth.

As is well known, a major requirement for the CMP process is the minimal dishing and erosion, as well as minimal levels of the surface defects [3]. Furthermore, approaching and even achieving the three-"zero" target of " $0 \mathrm{~nm}$ planarity, 0 defects, and 0 polishing load" are the desired goals for the CMP technology [5]. Hence, it is important to evaluate the surface defect of a $\mathrm{Cu}$ thin film. All the aforementioned results indicate that monolayer removal can be achieved under noncontact and monoatomic layer contact conditions at different water film thicknesses. The surface quality becomes better under thicker water films. With the scratching depth increasing to $0.5 \mathrm{~nm}$ and $1.0 \mathrm{~nm}$, an obvious groove with ridges along both sides is formed, and chips or debris are produced and accumulated in front of the particle. They increase the surface roughness and thereby lead to a deterioration of the surface quality. Moreover, the dislocation length is extracted and presented in Table 2 to evaluate the plastic deformation in the $\mathrm{Cu}$ thin film. It can be seen that at a scratching depth of $-0.2 \mathrm{~nm}$ and $0.1 \mathrm{~nm}$, no dislocations are activated in the scratching process at different water film thicknesses. These results are consistent with the experimental results in Refs. [4, 5], which indicated that a well-ordered crystalline surface could be clearly seen in the CMP generated subsurface and no damaged layers were found. However, the increase in the scratching depth induced the nucleation and propagation of the dislocations, for instance, the dislocation length increases dramatically from $28.57 \mathrm{~nm}$ to $108.01 \mathrm{~nm}$ as the scratching depth increases from $0.5 \mathrm{~nm}$ to $1.0 \mathrm{~nm}$. In addition, because the thickening of the water film decreases the interaction force between the rigid particle and $\mathrm{Cu}$ surface (Table 1), leading to a decrease in the stress acting on the $\mathrm{Cu}$ thin film, the dislocation length decreases as listed in Table 2.

\section{Conclusions}

In this work, MD simulation is employed to investigate the effect of the scratching depth on the atomic-scale removal behavior of a $\mathrm{Cu}$ thin film under an ultrathin water environment. The results indicate that monoatomic layer removal is achieved under noncontact and monoatomic layer contact conditions. The new surface is relatively smooth, and no deformed layer and plastic defects are present in the subsurface and within the $\mathrm{Cu}$ film. During the nanoscale processing, the water film transmits the forces from the loading of the abrasive particle to the $\mathrm{Cu}$ surface, and thereby results in the migration and then removal of the surface atoms. This is validated by the analysis of the interatomic interaction forces, and hence, the removal of the monoatomic layer is governed by the interatomic adhering action. However, as the scratching depth increases to $0.5 \mathrm{~nm}$ and $1.0 \mathrm{~nm}$, the particle interacts with the $\mathrm{Cu}$ substrate directly and the water film beneath the particle is easily squeezed out from the scratching region. This scratching process leads to the formation of an obvious groove and ridges along

Table 2 Dislocation length in monocrystalline $\mathrm{Cu}$.

\begin{tabular}{lcccccccccc}
\hline Water film thickness (nm) & \multicolumn{3}{c}{0.3} & \multicolumn{3}{c}{0.5} & \multicolumn{3}{c}{1.0} \\
\hline Scratch depth (nm) & -0.2 & 0.1 & 0.5 & -0.2 & 0.1 & 0.5 & -0.2 & 0.1 & 0.5 & 1.0 \\
Dislocation length (nm) & 0 & 0 & 65.55 & 0 & 0 & 42.33 & 0 & 0 & 28.57 & 108.01 \\
\hline
\end{tabular}


both sides of the groove, accumulation of numerous chips ahead of the particle, and dislocation generation within monocrystalline $\mathrm{Cu}$. There is a sharp increase in the interactive particle-Cu force with the increasing scratching depth. Therefore, the surface atoms are mainly removed by the plowing action of the abrasive particle, which increases the surface roughness and thereby leads to the deterioration of the surface quality. Clearly, the nanoscale surface process can be obtained by turning the contact conditions. It is known that for refined coatings or devices with nodes of $5 \mathrm{~nm}$ or smaller, a $0 \mathrm{~nm}$ planarity, zero residual defects and, possibly, zero polishing pressure are required. This study indicates that it is possible to bring the goals closer to us although we cannot achieve the goals immediately.

\section{Conflicts of interest}

The authors declare no conflict of interest. The funders had no role in the design of the study; in the collection, analyses, or interpretation of the data; in the writing of the manuscript, and in the decision to publish the results.

\section{Acknowledgements}

This work was supported by the National Natural Science Foundation of China [Grant numbers 51375364 and 51475359] and Natural Science Foundation of Shaanxi Province of China [2014JM6219].

Electronic Supplementary Material: Supplementary material is available in the online version of this article at https://doi.org/10.1007/s40544-019-0258-6.

Open Access: The articles published in this journal are distributed under the terms of the Creative Commons Attribution 4.0 International License (http:// creativecommons.org/licenses/by/4.0/), which permits unrestricted use, distribution, and reproduction in any medium, provided you give appropriate credit to the original author(s) and the source, provide a link to the Creative Commons license, and indicate if changes were made.

\section{References}

[1] Luo J F, Dornfeld D A. Material removal mechanism in chemical mechanical polishing: Theory and modeling. IEEE Trans Semicond Manuf 14(2): 112-133 (2001)

[2] Kasai T, Bhushan B. Physics and tribology of chemical mechanical planarization. J Phys: Condens Matter 20(22): 225011 (2008)

[3] Lu Z Y, Lee S H, Babu S V, Matijević E. The use of monodispersed colloids in the polishing of copper and tantalum. J Colloid Interface Sci 261(1): 55-64 (2003)

[4] Si L N, Guo D, Luo J B, Lu X C. Monoatomic layer removal mechanism in chemical mechanical polishing process: A molecular dynamics study. J Appl Phys 107(6): 064310 (2010)

[5] Tsujimura M. The way to zeros: The future of semiconductor device and chemical mechanical polishing technologies. J Appl Phys 55(6S3): 06JA01 (2016)

[6] Godin K, Cupo C, Yang E H. Reduction in step height variation and correcting contrast inversion in dynamic AFM of WS2 monolayers. Sci Rep 7: 17798 (2017)

[7] Kaufman F B, Thompson D B, Broadie R E, Jaso M A, Guthrie W L, Pearson D J, Small M B. Chemical-mechanical polishing for fabricating patterned $\mathrm{W}$ metal features as chip interconnects. J Electrochem Soc 138(11): 3460-3465 (1991)

[8] Zhao D W, Wang T Q, He Y Y, Lu X C. Effect of zone pressure on wafer bending and fluid lubrication behavior during multi-zone CMP process. Microelectron Eng 108: 33-38 (2013)

[9] Hung T C, Chang S H, Lin C C, Su Y T. Effects of abrasive particle size and tool surface irregularities on wear rates of work and tool in polishing processes. Microelectron Eng 88(9): 2981-2990 (2011)

[10] Ilie F. Tribochemical interaction between nanoparticles and surfaces of selective layer during chemical mechanical polishing. J Nanopart Res 15(11): 1997 (2013)

[11] Zhu P Z, Hu Y Z, Ma T B, Wang H. Molecular dynamics study on friction due to ploughing and adhesion in nanometric scratching process. Tribol Lett 41(1): 41-46 (2011)

[12] Luo Q, Campbell D R, Babu S V. Stabilization of alumina slurry for chemical-mechanical polishing of copper. Langmuir 12(15): 3563-3566 (1996)

[13] Su Y T. Investigation of removal rate properties of a floating polishing process. J Electrochem Soc 147(6): 2290-2296 (2000)

[14] Patri U B, Pandija S, Babu S V. Role of molecular structure of complexing/chelating agents in copper CMP slurries. Mater Res Soc Symp Proc 867: W1.11 (2005)

[15] Barthel A J, Al-Azizi A, Surdyka N D, Kim S H. Effects of gas or vapor adsorption on adhesion, friction, and wear of solid interfaces. Langmuir 30(11): 2977-2992 (2014) 
[16] Chen X C, Zhao Y W, Wang Y G, Zhou H L, Ni Z F, An W. Nanoscale friction and wear properties of silicon wafer under different lubrication conditions. Appl Surf Sci 282: 25-31 (2013)

[17] Ren J Q, Zhao J S, Dong Z G, Liu P K. Molecular dynamics study on the mechanism of AFM-based nanoscratching process with water-layer lubrication. App Surf Sci 346: 84-98 (2015)

[18] Shi J Q, Chen J, Fang L, Sun K, Sun J P, Han J. Atomistic scale nanoscratching behavior of monocrystalline $\mathrm{Cu}$ influenced by water film in CMP process. App Surf Sci 435 : 983-992 (2018)

[19] Chen Y, Li Z N, Miao N M. Polymethylmethacrylate (PMMA) $/ \mathrm{CeO}_{2}$ hybrid particles for enhanced chemical mechanical polishing performance. Tribol Int 82: 211-217 (2015)

[20] Mishin Y, Mehl M J, Papaconstantopoulos D A, Voter A F, Kress J D. Structural stability and lattice defects in copper: $\mathrm{Ab}$ initio, tight-binding, and embedded-atom calculations. Phys Rev B 63(22): 224106 (2001)

[21] Morse P M. Diatomic molecules according to the wave mechanics. II. Vibrational levels. Phys Rev 34(1): 57-64 (1929)

[22] Imran M, Hussain F, Rashid M, Ahmad S A. Molecular dynamics study of the mechanical characteristics of $\mathrm{Ni} / \mathrm{Cu}$ bilayer using nanoindentation. Chin Phys B 21(12): 126802 (2012)

[23] Chang W Y, Fang T H, Lin S J, Huang J J. Nanoindentation response of nickel surface using molecular dynamics simulation. Mol Simul 36(11): 815-822 (2010)

[24] Khan H M, Kim S G. On the wear mechanism of thin nickel film during AFM- based scratching process using molecular dynamics. J Mech Sci Technol 25(8): 2111-2120 (2011)

[25] Abascal J L F, Vega C. A general purpose model for the condensed phases of water: TIP4P/2005. J Chem Phys 123(23): 234505 (2005)

[26] Shi J Q, Zhang Y N, Sun K, Fang L. Effect of water film on

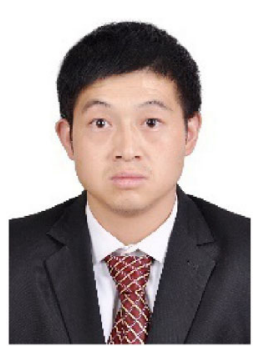

Junqin SHI. He received his M.S. degree in physics in 2015 from China University of Petroleum (East China), China. After then, he was a Ph.D. student in the State Key Laboratory for Mechanical Behavior of Materials the plastic deformation of monocrystalline copper. RSC $A d v$ 6(99): 96824-96831 (2016)

[27] Gao Y, Ruestes C J, Urbassek H M. Nanoindentation and nanoscratching of iron: Atomistic simulation of dislocation generation and reactions. Comput Mater Sci 90: 232-240 (2014)

[28] Stukowski A, Albe K. Extracting dislocations and nondislocation crystal defects from atomistic simulation data. Model Simul Mater Sci Eng 18(8): 085001 (2010)

[29] Stukowski A. Visualization and analysis of atomistic simulation data with OVITO-the open visualization tool. Model Simul Mater Sci Eng 18(1): 015012 (2010)

[30] Luo J F, Dornfeld D A. Material removal regions in chemical mechanical planarization for submicron integrated circuit fabrication: Coupling effects of slurry chemicals, abrasive size distribution, and wafer-pad contact area. IEEE Trans Semicond Manuf 16(1): 45-56 (2003)

[31] Shiari B, Miller R E, Klug D D. Multiscale simulation of material removal processes at the nanoscale. $J$ Mech Phys Solids 55(11): 2384-2405 (2007)

[32] Thiel P A, Madey T E. The interaction of water with solid surfaces: Fundamental aspects. Surf Sci Rep 7(6-8): 211-385 (1987)

[33] Henderson M A. The interaction of water with solid surfaces: Fundamental aspects revisited. Surf Sci Rep 46(1-8): 1-308 (2002)

[34] Held G, Menzel, D. The structure of the $\mathrm{p}(\sqrt{ } 3 \times \sqrt{ } 3) \mathrm{R} 30^{\circ}$ bilayer of $\mathrm{D}_{2} \mathrm{O}$ on $\mathrm{Ru}(001)$. Surf Sci 316(1-2): 92-102 (1994)

[35] Meng S, Wang E G, Gao S W. Water adsorption on metal surfaces: A general picture from density functional theory studies. Phys Rev B 69(19): 195404 (2004)

[36] Hodgson A, Haq S. Water adsorption and the wetting of metal surfaces. Surf Sci Rep 64(9): 381-451 (2009)

[37] Bhushan B. Springer Handbook of Nanotechnology. Berlin, Heidelberg (Germany): Springer, 2013: 82-83.

[38] Raviv U, Laurat P, Klein J. Fluidity of water confined to subnanometre films. Nature 413(6851): 51-54 (2001)

at Xi'an Jiaotong University, China. He has recently obtained his Ph.D. degree in materials science and engineering at Xi'an Jiaotong University. His research interests include plastic deformation, friction and wear behavior of crystal materials, and the computational materials science. 


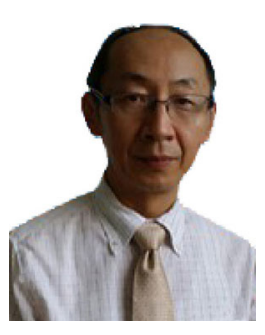

Liang FANG. He received his M.S. and Ph.D. degrees in materials science and engineering from Xi'an Jiaotong University and Harbin Institute of Technology, China, in 1984 and 1991, respectively. His current position is

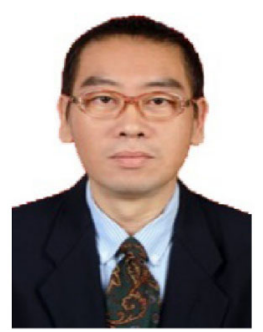

Kun SUN. He received his M.S. and Ph.D. degrees in engineering mechanics and mechanical engineering from Xi'an Jiaotong University, China, in 1997 and 2001 respectively. He a professor in the State Key Laboratory for Mechanical Behavior of Materials at Xi'an Jiaotong University and the dean of School of Mechanical and Electrical Engineering in Xiamen University Tan KahKee College. His research areas cover the tribology and processing of metallic materials.

joined the State Key Laboratory for Mechanical Behavior of Materials at Xi'an Jiaotong University from 2003. His research areas cover the engineering mechanics and tribology of metallic materials, and the materials genome. 